Supporting Information for

\title{
Thermally Conductive Graphene Films for Heat Dissipation
}

Guang Yang ${ }^{1}$, Haokun $\mathrm{Yi}^{1}$, Yagang Yao ${ }^{2 *}$, Chaowei $\mathrm{Li}^{2}$, Zhuo $\mathrm{Li}^{1 *}$

${ }^{1}$ Department of Materials Science, Fudan University, Shanghai 200433, China

${ }^{2}$ National Laboratory of Solid State Microstructures, College of Engineering and Applied Sciences, Jiangsu Key Laboratory of Artificial Functional Materials, and Collaborative Innovation Center of Advanced Microstructures, Nanjing University, Nanjing 210093, China

*E-mail: zhuo_li@fudan.edu.cn; ygyao2018@nju.edu.cn 


\section{Supplementary Text}

\section{$\underline{\text { Structural characterization and size measurement of GO sheets }}$}

LGGO sheets and SMGO sheets from the GO solution of the same concentration are characterized through the AFM and SEM images shown in Fig. S2 and S4. The SEM pictures of surface and crosssection of the rGO films fabricated from LGGOs combined with SMGOs from $10 \mathrm{wt} \%$ to 90 wt\% are shown in Fig. S7. The SEM images of LGGO and SMGO sheets on a silicon wafer are also illustrated to obtain the corresponding size distribution depicted in Fig. S4. Raman characterization of diluted GO dispersion on silicon wafer followed by chemical reduction with hydriodic acid/acetic acid (vapor) at $60{ }^{\circ} \mathrm{C}$ for $6 \mathrm{~h}^{1}$ was performed and demonstrated in Fig. S3. As a result, the average sizes of LGGOs and SMGOs are about $15.83 \mu \mathrm{m}$ (dispersity 1.20) and $3.05 \mu \mathrm{m}$ (dispersity 1.07) respectively. The AFM images of LGGO and SMGO sheets on a silicon wafer are shown in Fig. S2 and the average height of the monolayer GO sheets is around $1 \mathrm{~nm}$. The defect density of rGO monolayers is calculated from the Raman spectra in Fig. S3: according to reference 2, the average distance between structural defects $\left(L_{D}\right)$ can be determined as $1.58 \mathrm{~nm}$ and the defect density can be obtained as $1.27 \times 10^{13} \mathrm{~cm}^{-2}$.

\section{$\underline{\text { XPS spectra and XRD patterns of the graphene films after chemical reduction }}$}

In order to prove the reduction effectiveness of HI, the films fabricated from GO solution of the same concentration have been tested by XPS before and after HI reduction and the results are shown in Fig. S5. The XPS spectra imply the removal of oxygen functional groups from the graphene sheets after reduction because of the decline in the O1s peaks. Furthermore, the series of XPS spectra of reduced 
graphene films with different contents of SMGOs depicted in Fig. S6 (a) (relative peak areas are shown in Table S2) indicate that the reduction level of all samples are similar and inferior to that after hightemperature annealing. The XRD patterns are shown in Fig. S6 (b). The peak position is almost identical for all samples, indicating the same inter-layer distance after reduction (according to the Bragg's law).

\section{Geometry simulation of the packing of graphene sheets}

To conduct the simulation of the relation between the compactness and the content of SMGOs, a premise has been utilized that the irregular packing of graphene sheets can be replaced by the packing of circles. However, the diameters of the circles are still kept in line with the actual lateral size of graphene sheets. Fig. 4 (a-e) shows the modeling of the packing of LGGO sheets at different contents (according to reference ${ }^{11-14}$ ) and the mean distances between LGGO sheets of different contents can be statistically calculated through all interstitial spaces in these models. Fig. S8 demonstrates the decline in compactness as the increase in the SMGO sheets which are also geometrically simulated by smaller circles. Note that the ideal compactness is calculated by the area proportion of all circles (the diameter of the larger circle is five times of the smaller one) in infinite 2D plane which filled with periodic packing patterns (green insets).

The thermal conductivity measured by the Improved Thermal Bridge (ITB) method

The ITB method was conducted to verify the test results of the laser flash method. The ITB method is a modified version of standard thermal bridge method and the setup is shown in Figure S9. The graphene film was fixed between two sapphire pillars and homemade resistors (served as both heater and 
thermometer) were attached to both pillars with silver paste (SPI-PAINT 05001-AB). The device was heated in an oven at $100{ }^{\circ} \mathrm{C}$ for $30 \mathrm{~min}$, and then put in a cryostat (vacuum degree less than $1 \times 10^{-3} \mathrm{~Pa}$ ) to prevent thermal convection.

A DC current combined with an AC current was applied to the left resistor. The DC current could provide Joule heat while the AC current was used for resistance measurement. At the steady state, the temperature gradient between two ends of the graphene film could be determined by the change of resistance of the two resistors, which can be used to obtain the thermal resistance of the graphene sample. This thermal resistance includes two parts, namely the thermal resistance of the graphene film sample and the contact resistance between the sample and the sapphire pillar. The effect contact resistance can be eliminated by measuring the graphene sample with different length, during which the contact resistance remains the same while the thermal resistance of the graphene film decreases with the sample length.

The detailed mechanism of this method could be found in reference 15. Simply speaking, the thermal conductivity $k$ could be calculated from the relation between $R s \times w \times d$ and $L$, which is:

$R_{s} X_{w} \times d=L \times k^{-1}+R_{c} X_{w} \times d$

where $R_{S}$ is the measured thermal resistance of the sample; $w, d, L$ are the width, thickness and length of our graphene film and $R_{c}$ is the thermal contact resistance. As a result, the thermal conductivity $k$ of the optimum graphene films (50 wt $\%$ SMGOs) was $1146.59 \mathrm{~W} \cdot \mathrm{m}^{-1} \cdot \mathrm{K}^{-1}$ by linear fitting in Figure S10. The difference between the results of LFA and ITB was less than $5 \%$. 


\section{Supplementary Figures}
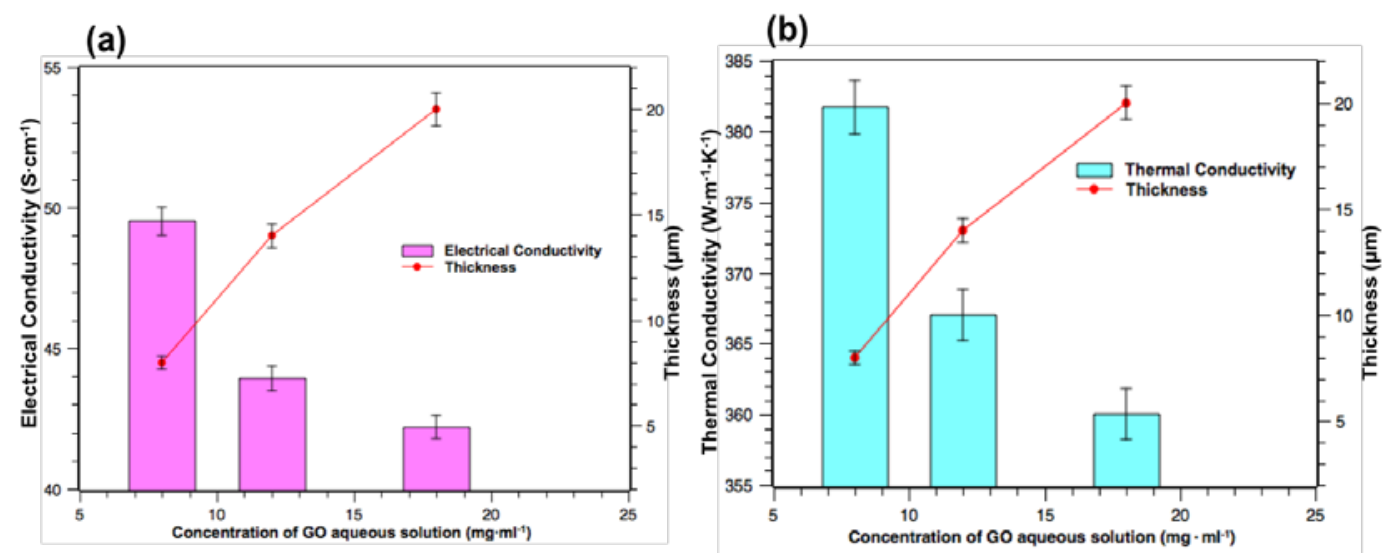

Figure S1. (a) Electrical and (b) thermal conductivities and the thickness of the rGO films fabricated from different concentrations of GO solutions. 

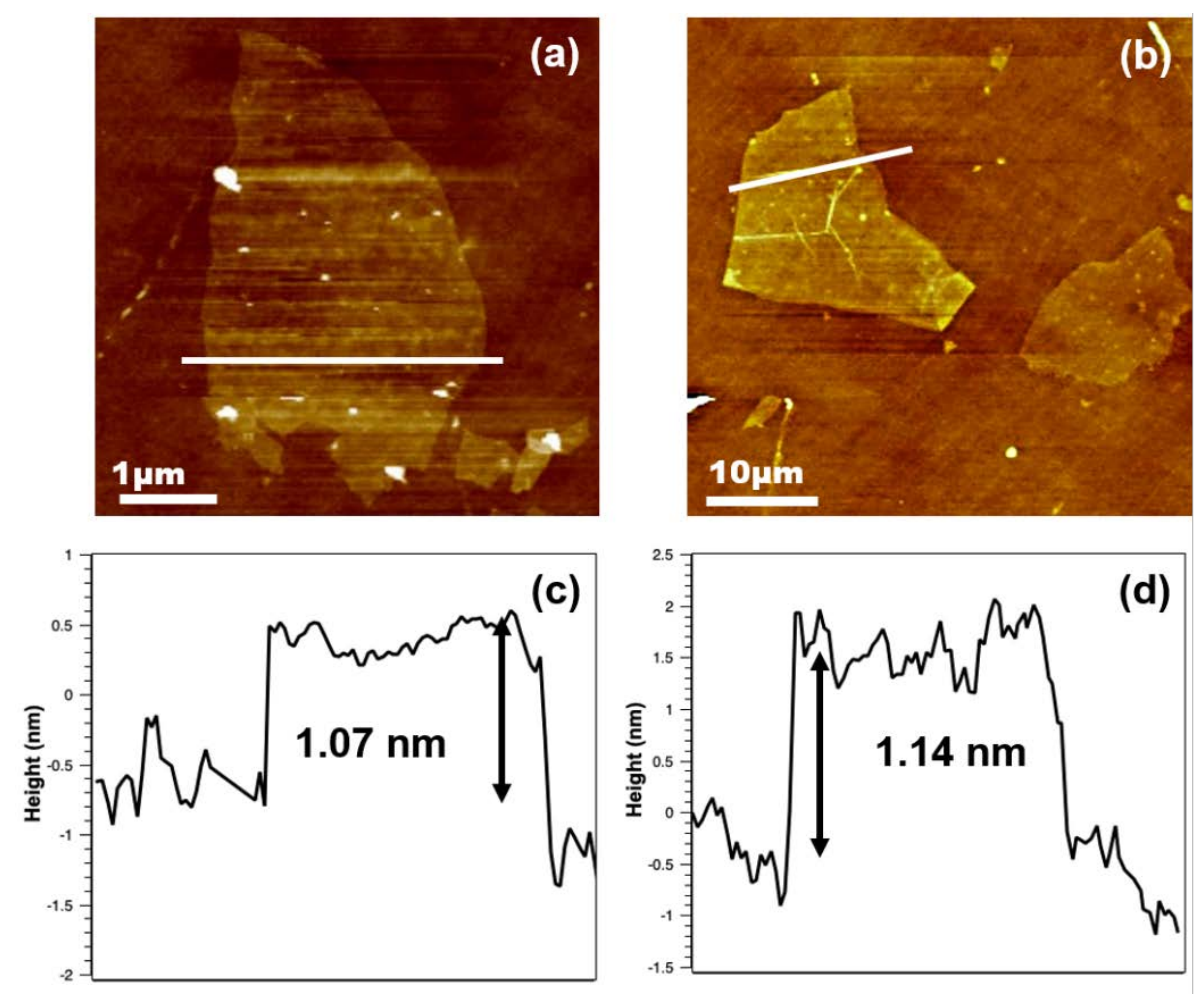

Figure S2. AFM characterizations of SMGOs ((a) and (c)) and LGGOs ((b) and (d)). 


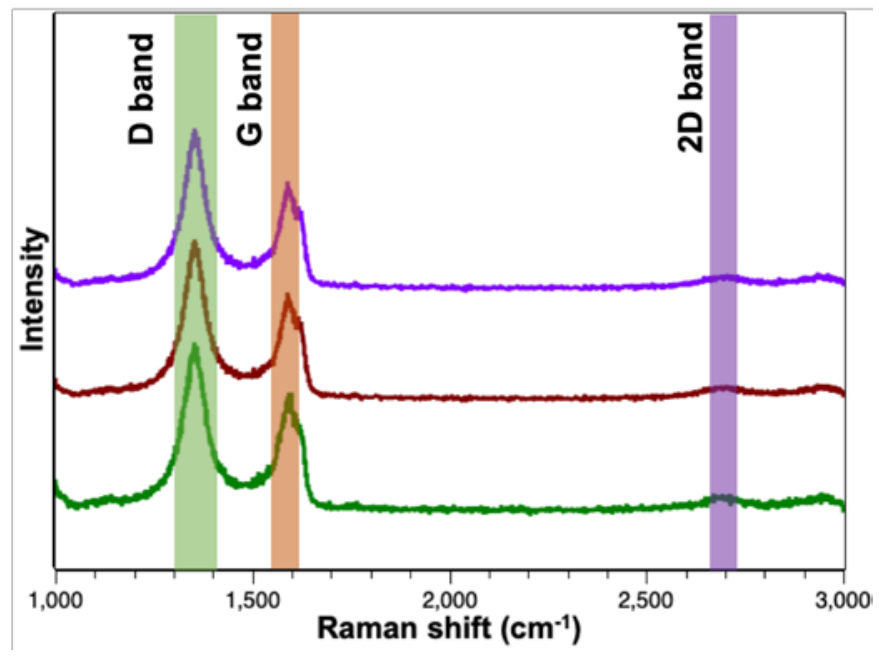

Figure S3. Raman spectra of rGO monolayers. 

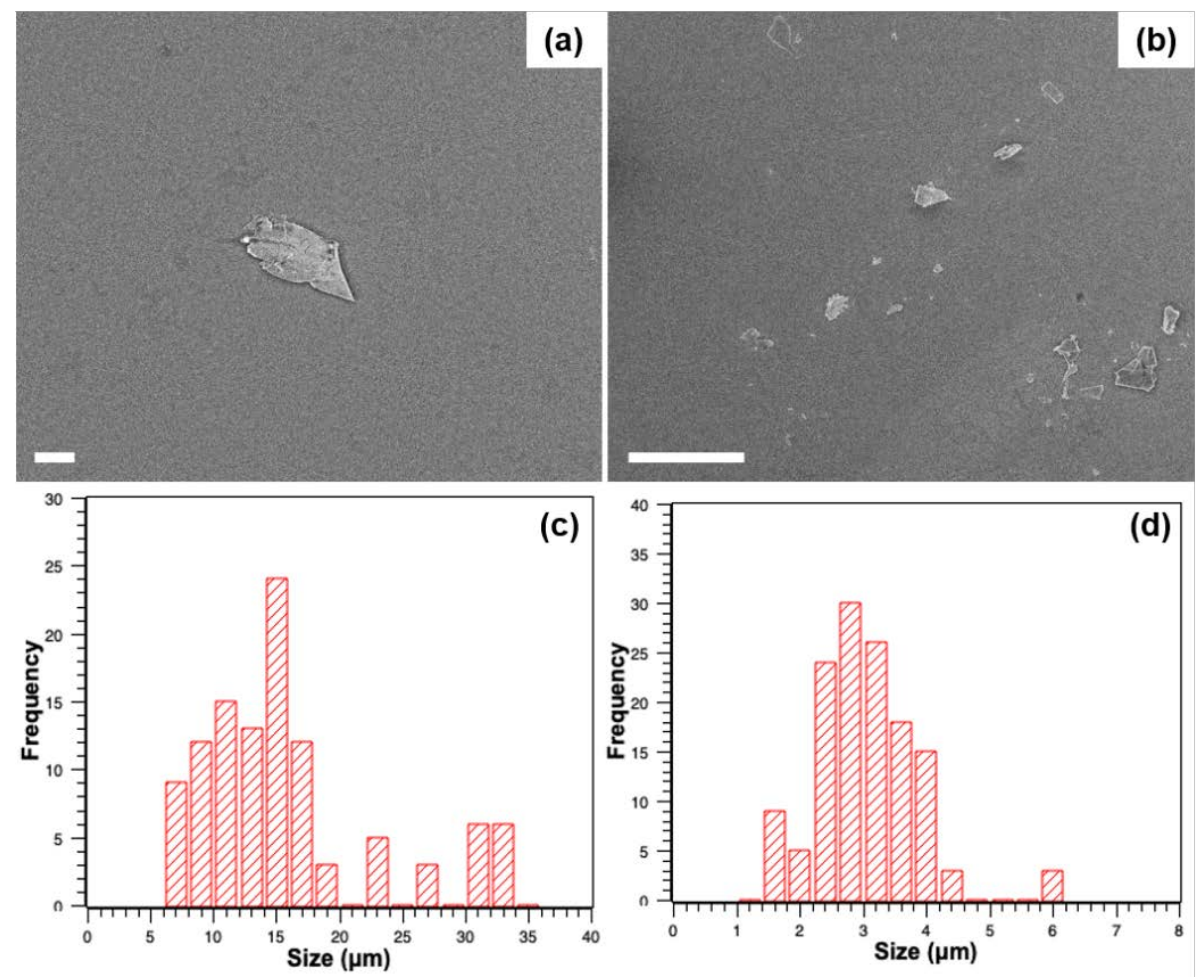

Figure S4. SEM images of (a) LGGOs and (b) SMGOs, scale bar represents for $10 \mu \mathrm{m}$; size distribution of (c) LGGOs and (d) SMGOs. 

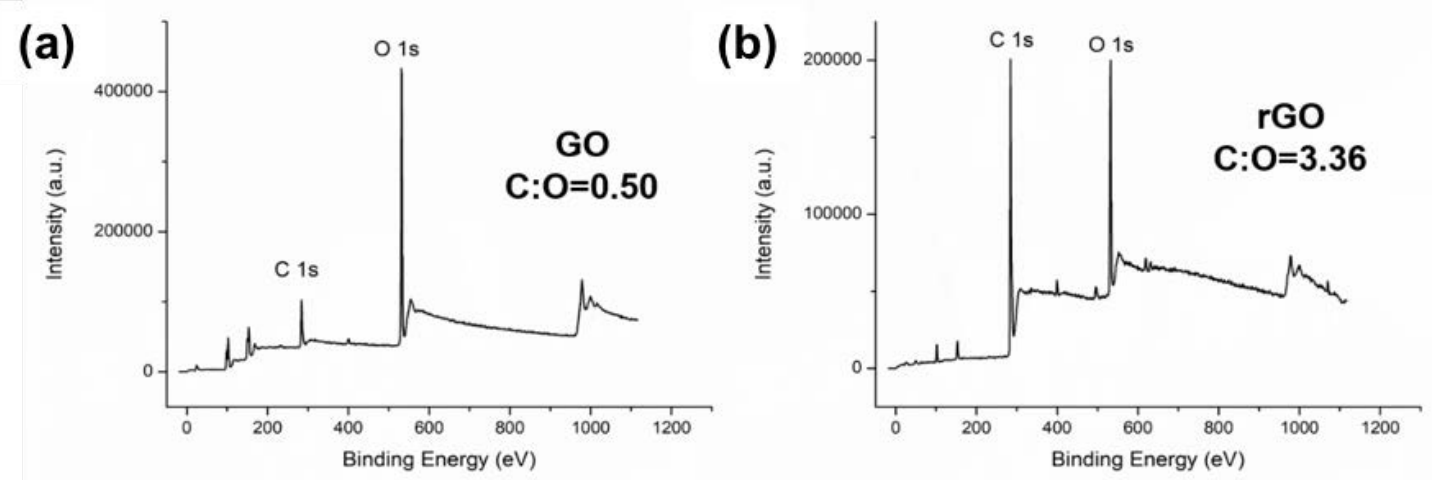

Figure S5. XPS spectra of the films of (a) GOs and (b) rGOs annotated with carbon to oxygen ratios. 
(a)

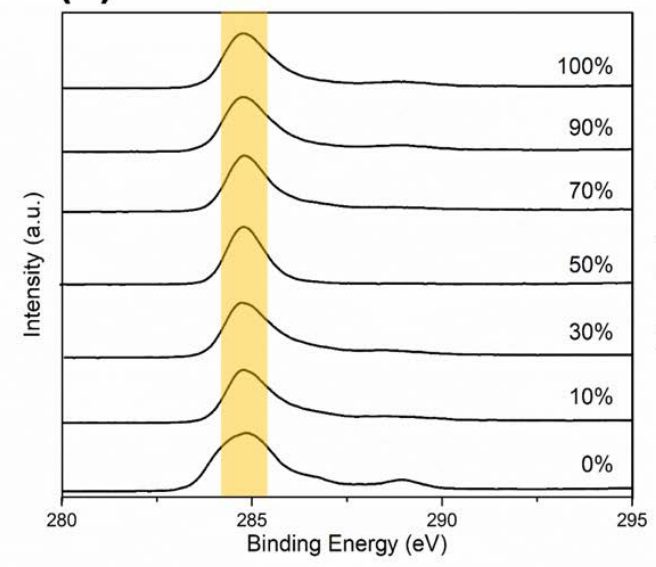

(b)

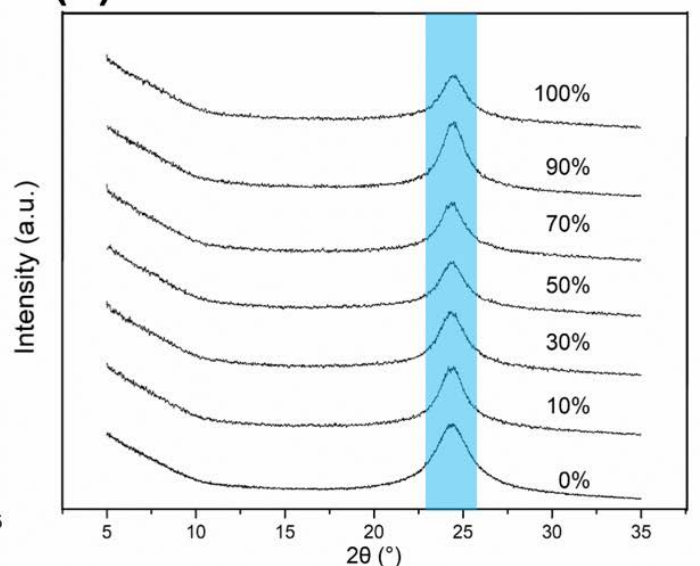

Figure S6. (a) C1s XPS spectra and (b) XRD patterns of the rGO films from different contents of SMGOs. 

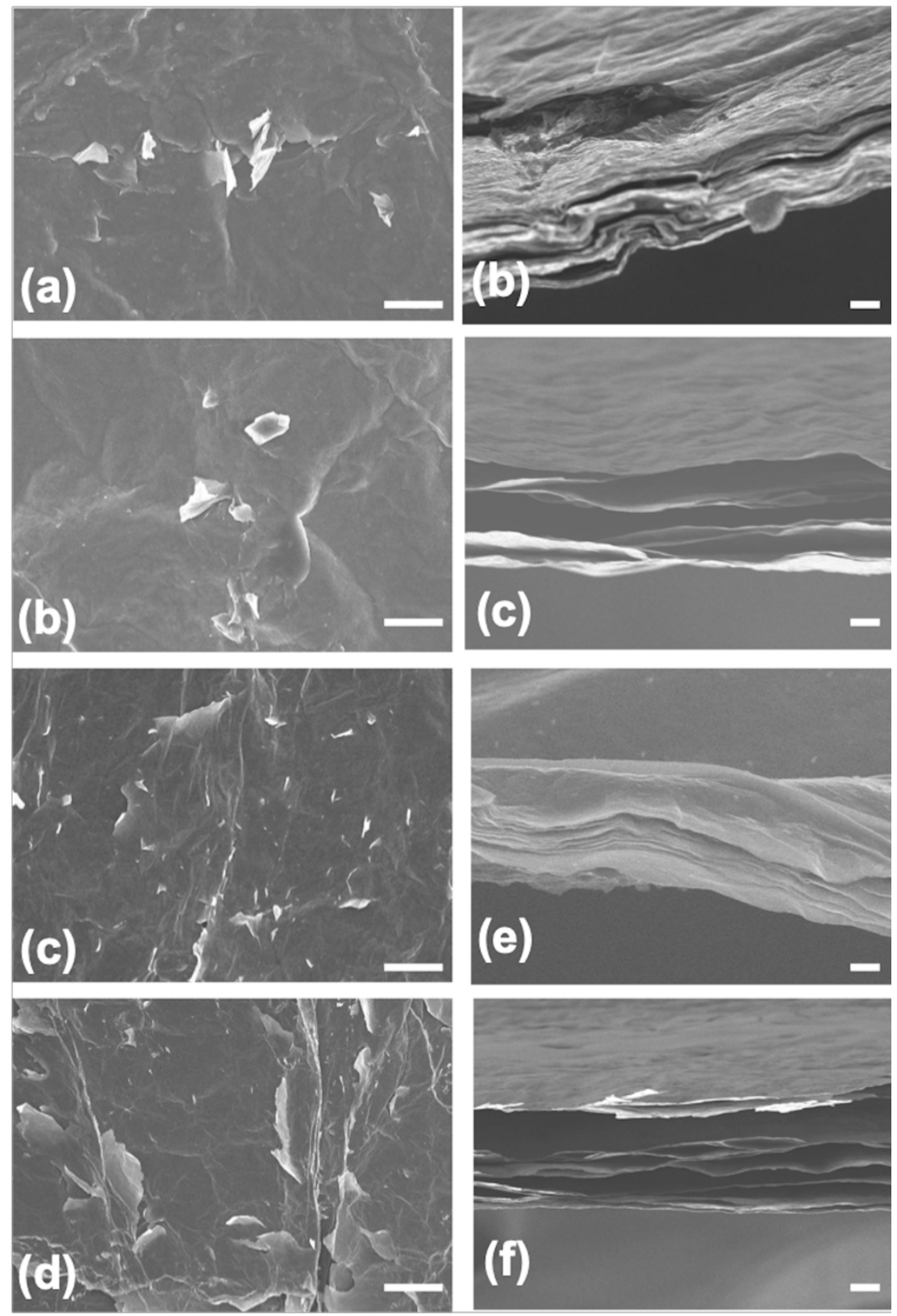

Figure S7. SEM images showing inner structure of the rGO films fabricated from LGGOs combined with 10 wt\% SMGOs ((a) and (e)); 30 wt\% SMGOs ((b) and (f)); 70 wt\% SMGOs ((c) and (g)); 90 wt\% SMGOs ((d) and (h)). Note that (a-d) are surface pictures while (e-h) are cross-section pictures. The scale bars represent for $2 \mu \mathrm{m}$. 


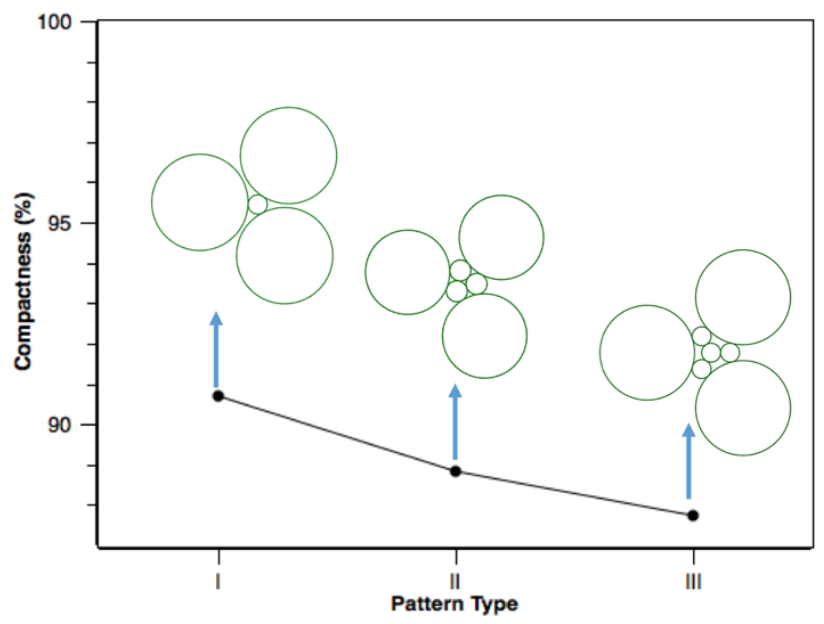

Figure S8. Simulation of the compactness of different packing patterns as the SMGO content increases. 


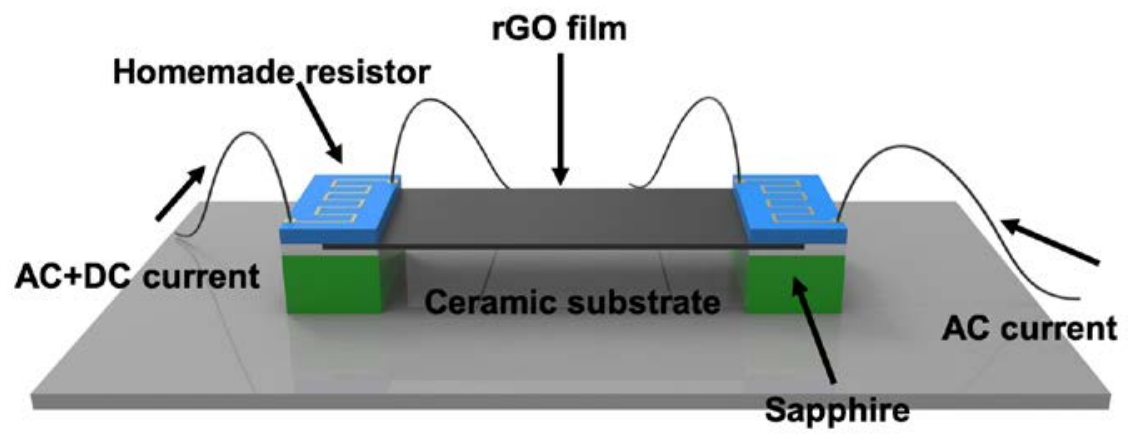

Figure S9. Schematic diagram of the ITB method. 


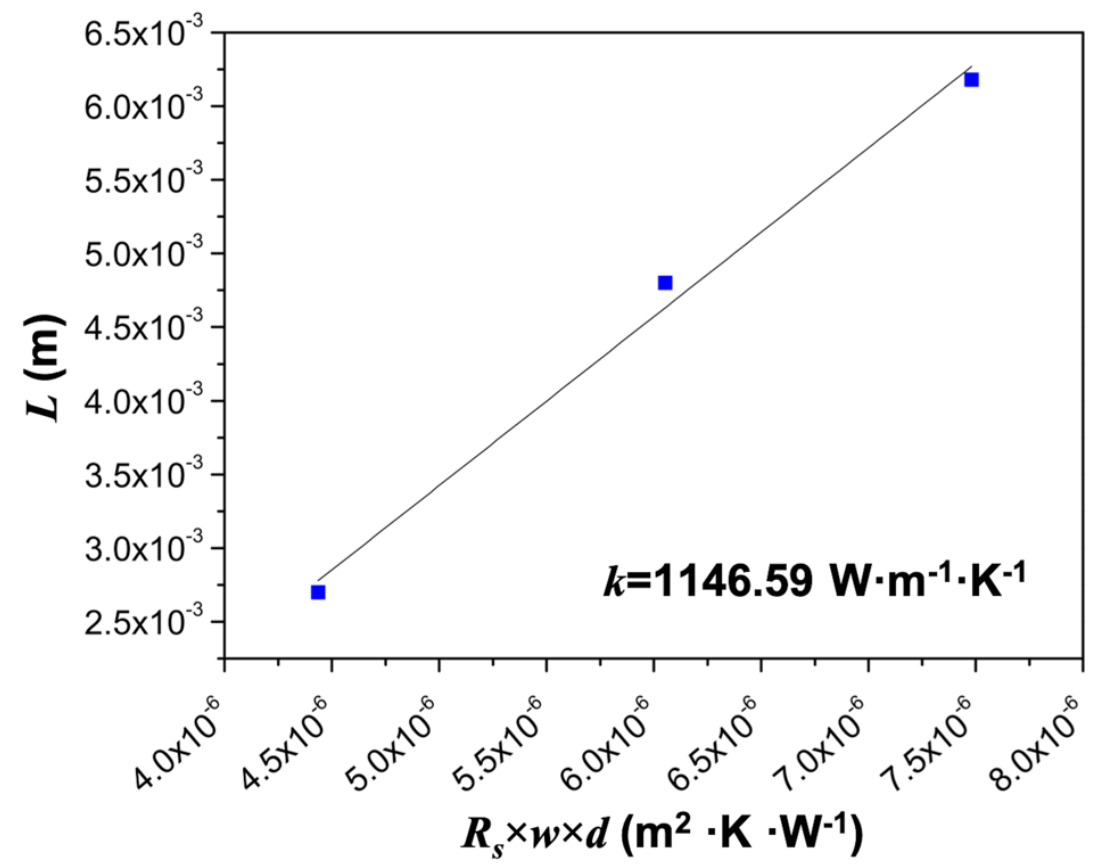

Figure S10. The results of length dependence in the ITB method for verifying the thermal conductivity of graphene films with 50 wt\% SMGOs. 
Table S1. Comparison of the thermally conductive graphene films fabricated from different raw materials through different preparation and reduction methods

\begin{tabular}{|c|c|c|c|c|}
\hline $\begin{array}{l}\text { Raw } \\
\text { materials }\end{array}$ & $\begin{array}{l}\text { Preparation } \\
\text { methods }\end{array}$ & Reduction & $\begin{array}{l}\text { Thermal } \\
\text { Conductivities } \\
\left(\mathrm{W} \cdot \mathrm{m}^{-1} \cdot \mathrm{K}^{-1}\right)\end{array}$ & Limitations \\
\hline Graphite & $\begin{array}{l}\text { Liquid } \\
\text { exfoliation, } \\
\text { filtration }\end{array}$ & $\begin{array}{l}\text { Hot press } \\
\left(340^{\circ} \mathrm{C}\right. \\
1000 \mathrm{MPa})\end{array}$ & $313^{3}$ & $\begin{array}{l}\text { Difficult to control the } \\
\text { thickness of films, highly } \\
\text { time-consuming }\end{array}$ \\
\hline Graphite & $\begin{array}{l}\text { Electroche- } \\
\text { mical } \\
\text { exfoliation, } \\
\text { filtration }\end{array}$ & $\begin{array}{l}\text { Annealing } \\
\left(150^{\circ} \mathrm{C}\right) \\
\mathrm{H}_{2} 5 \%-\mathrm{Ar}\end{array}$ & $658^{4}$ & $\begin{array}{l}\text { Difficult to control the } \\
\text { thickness of films, highly } \\
\text { consuming }\end{array}$ \\
\hline Graphite & $\begin{array}{l}\text { Roll- } \\
\text { compacting }\end{array}$ & -- & $486^{5}$ & $\begin{array}{l}\text { Difficult to control the } \\
\text { shape and geometry of } \\
\text { films, highly time-and- } \\
\text { energy-consuming }\end{array}$ \\
\hline Graphene & ESD & $\begin{array}{l}\text { Annealing } \\
\left(1800^{\circ} \mathrm{C}\right)\end{array}$ & $809.5^{6}$ & $\begin{array}{l}\text { Highly energy- } \\
\text { consuming, demanding in } \\
\text { devices }\end{array}$ \\
\hline GO & $\begin{array}{l}\text { Solvent } \\
\text { evaporation }\end{array}$ & $\begin{array}{l}\text { Annealing } \\
\left(1000^{\circ} \mathrm{C},\right. \\
\left.\text { with } \mathrm{N}_{2}\right)\end{array}$ & $61^{7}$ & $\begin{array}{l}\text { Difficult to control the } \\
\text { thickness and quality of } \\
\text { films, highly time-and- } \\
\text { energy-consuming }\end{array}$ \\
\hline GO & $\begin{array}{l}\text { Vacuum } \\
\text { filtration }\end{array}$ & $\begin{array}{l}\mathrm{HI} \\
\text { reduction }\end{array}$ & $900 \pm 45^{8}$ & $\begin{array}{l}\text { Difficult to control the } \\
\text { thickness and quality of }\end{array}$ \\
\hline GO & $\begin{array}{l}\text { Vacuum } \\
\text { filtration }\end{array}$ & $\begin{array}{l}\text { Annealing } \\
\left(1200^{\circ} \mathrm{C}\right)\end{array}$ & $1043.5^{9}$ & $\begin{array}{l}\text { films, highly time-and- } \\
\text { energy-consuming, size } \\
\text { restrictive to filter } \\
\text { membrane }\end{array}$ \\
\hline GO & $\begin{array}{l}\text { Roller } \\
\text { coating }\end{array}$ & $\begin{array}{l}\text { Annealing } \\
\left(2800^{\circ} \mathrm{C}\right)\end{array}$ & $826^{10}$ & $\begin{array}{l}\text { Difficult to control the } \\
\text { quality and uniformity of } \\
\text { films, demanding in } \\
\text { energy and devices }\end{array}$ \\
\hline
\end{tabular}


Table S2. Relative peak areas (\%) of C1s XPS spectra from Fig. S6(a)

\begin{tabular}{|c|c|c|c|c|c|c|c|c|}
\hline \multicolumn{2}{|l|}{ SMGO wt\% } & \multirow{2}{*}{0} & \multirow{2}{*}{10} & \multirow{2}{*}{30} & \multirow{2}{*}{50} & \multirow{2}{*}{70} & \multirow{2}{*}{90} & \multirow{2}{*}{100} \\
\hline Element & $\begin{array}{l}\text { B.E. } \\
(\mathrm{eV})\end{array}$ & & & & & & & \\
\hline $\mathrm{C}-\mathrm{C} / \mathrm{C}=\mathrm{C}$ & 284.8 & 65.47 & 63.26 & 67.78 & 66.26 & 66.79 & 68.95 & 61.49 \\
\hline $\mathrm{C}-\mathrm{O}-\mathrm{C} / \mathrm{C}-\mathrm{OH}$ & 286.5 & 23.58 & 25.15 & 20.43 & 23.46 & 27.35 & 21.21 & 28.44 \\
\hline $\mathrm{COOH}$ & 289.0 & 10.95 & 11.59 & 11.79 & 10.29 & 5.86 & 9.84 & 10.07 \\
\hline
\end{tabular}


Table S3. The thickness and density of the rGO films produced in this work

\begin{tabular}{|c|c|c|c|c|c|c|c|}
\hline $\begin{array}{l}\text { SMGO } \\
\text { wt\% }\end{array}$ & 0 & 10 & 30 & 50 & 70 & 90 & 100 \\
\hline $\begin{array}{l}\text { Thickness } \\
(\mu \mathrm{m})\end{array}$ & 7.71 & 7.09 & 9.32 & 8.40 & 6.96 & 9.58 & 8.32 \\
\hline $\begin{array}{l}\text { Density } \\
\left(\mathrm{g} \cdot \mathrm{cm}^{-3}\right) \\
\text { before } \\
\text { mechanical } \\
\text { press }\end{array}$ & 0.52 & 0.54 & 0.55 & 0.96 & 0.82 & 0.48 & 0.42 \\
\hline $\begin{array}{l}\text { Density } \\
\left(\mathrm{g} \cdot \mathrm{cm}^{-3}\right) \\
\text { after } \\
\text { mechanical } \\
\text { press }\end{array}$ & 0.70 & 0.73 & 0.74 & 1.43 & 1.11 & 0.65 & 0.57 \\
\hline
\end{tabular}


Table S4. The thermal diffusivity and thermal capacity of different rGO films.

\begin{tabular}{llllllll}
\hline $\begin{array}{l}\text { SMGO } \\
\text { wt\% }\end{array}$ & 0 & 10 & 30 & 50 & 70 & 90 & 100 \\
\hline $\begin{array}{c}\text { Thermal } \\
\text { diffusivity } \\
\left(\mathrm{mm}^{2} \cdot \mathrm{s}^{-1}\right)\end{array}$ & 687.7 & 688.1 & 959.3 & 987.28 & 828.42 & 650.38 & 701.29 \\
$\begin{array}{c}\text { Thermal } \\
\text { capacity }\end{array}$ & 0.791 & 0.788 & 0.785 & 0.781 & 0.776 & 0.773 & 0.768 \\
$\left(\mathrm{~J} \cdot \mathrm{g}^{-1} \cdot \mathrm{K}^{-1}\right)$ & & & & & & & \\
\hline
\end{tabular}

\section{References}

(1) Chen, H.; Wu, M.; Li, C. Enhancing Graphene-Based Film Materials by Reducing Planar Defects rather than Flake Boundary. Carbon 2018, 139, 216-225.

(2) Cancado, L.; Jorio,; Ferreira, E.; Stavale, F.; Achete, C.; Capaz, R.; Moutinho, M.; Lombardo, A.; Kulmala, T.; Ferrari, A. Quantifying Defects in Graphene via Raman Spectroscopy at Different Excitation Energies. Nano Lett. 2011, 11 (8), 3190-3196.

(3) Wang, D.; Song, P.; Liu, C.; Wu, W.; Fan, S. Highly Oriented Carbon Nanotube Papers Made Of Aligned Carbon Nanotubes. Nanotechnology, 2008, 19, 075609.

(4) Li, C.; Xu, Y.; Zhao, B.; Jiang, L.; Chen, S.; Xu, J.; Fu, X.; Sun, R.; Wong, C. Flexible Graphene Electrothermal Films Made from Electrochemically Exfoliated Graphite. J Mater Sci, 2016, 51, 1043-1051.

(5) Liu, R.; Chen, J.; Tan, M.; Song, S.; Chen, Y.; Fu, D. Anisotropic High Thermal Conductivity of Flexible Graphite Sheets Used for Advanced Thermal Management Materials. 2013 International 
Conference on Materials for Renewable Energy and Environment, 2013, 1-3, 107-111.

(6) Xin, G.; Sun, H.; Hu, T.; Fard, H.; Sun, X.; Koratkar, N.; Borca-Tasciuc, T.; Lian, J. Large-Area Freestanding Graphene Paper for Superior Thermal Management. Adv Mater, 2014, 26, 4521-4526.

(7) Renteria, J.; Ramirez, S.; Malekpour, H.; Alonso, B.; Centeno, A.; Zurutuza, A.; Cocemasov, A.; Nika, D.; Balandin, A. Strongly Anisotropic Thermal Conductivity of Free-Standing Reduced Graphene Oxide Films Annealed at High Temperature. Advanced Functional Materials, 2015, 25, 4664-4672.

(8) Kumar, P.; Shahzad, F.; Yu, S.; Hong, S.; Kim, Y.; Koo, C. Large-area Reduced Graphene Oxide Thin Film with Excellent Thermal Conductivity and Electromagnetic Interference Shielding Effectiveness. Carbon, 2015, 94, 494-500.

(9) Song, N.; Chen, C.; Lu, C.; Liu, Z.; Kong, Q.; Cai, R. Thermally Reduced Graphene Oxide Films as Flexible Lateral Heat Spreaders. J Mater Chem A, 2014, 2, 16563-16568.

(10) Huang, Y.; Gong, Q.; Zhang, Q.; Shao, Y.; Wang, J.; Jiang, Y.; Zhao, M.; Zhuang, D.; Liang, J. Fabrication and Molecular Dynamics Analyses of Highly Thermal Conductive Reduced Graphene Oxide Films at Ultra-High Temperatures. Nanoscale, 2017, 9, 2340-2347.

(11) Boll, D.; Donovan, J.; Graham, R.; Lubachevsky, B. Improving Dense Packings of Equal Disks in a Square. The Electronic Journal of Combinatorics, 2000, 7, 46. DeGroot, C.; Peikert, R.; Würtz, D. The Optimal Packing of Ten Equal Circles in a Square. System Modelling and Optimization, Lecture Notes in Control and Information Sciences; Springer International Publishing: Berlin, 1992. 
(13) Markot, M.; Csendes, T. A New Verified Optimization Technique for the "Packing Circles in a Unit Square" Problems. Siam J. Optimiz., 2005, 16, 193-219.

(14) Szabó, P.; Specht, E. Packing up to 200 Equal Circles in a Square. Models and Algorithms for Global Optimization; Springer-International Publishing: Berlin, 2007, 141-156.

(15) Wang, N.; Samani, M.; Li, H.; Dong, L.; Zhang, Z.; Su, P.; Chen, S.; Chen, J.; Huang, S.; Yuan, G.; Xu, X.; Li, B.; Leifer, K.; Ye, L.; Liu, J. Tailoring the Thermal and Mechanical Properties of Graphene Film by Structural Engineering. Small 2018, 1801346. 